\title{
Correlation Between Density of Residential Areas and Solar Energy Potential in Xining City
}

\author{
Ting Wen ${ }^{1}, Y u$ Liu $^{1, *}$, Jin Wang ${ }^{1}$, Wuxing Zheng ${ }^{1}$, and Teng Shao ${ }^{1}$ \\ ${ }^{1}$ Northwestern Polytechnical University, Sustainable Building and Environmental Research Institute, \\ 127 Youyi West Road, Xi'an, Shaanxi, 710072, China
}

\begin{abstract}
In urban scale, solar energy utilization potential is closely related to residential density. Taking Xining City as an example, this paper explored how density of urban residential area affects solar energy utilization potential of urban housing. By changing density related design variables, including building layout, density rate, floor-site area ratio and the number of floors, 36 general models of residential areas with low, medium and high density are abstracted. The results show that solar energy utilization potential of buildings varies greatly with different density related design variables. Comparison of a number of different scenarios reveals how density related variables affect solar energy utilization potential, based on which suggestions for optimization of solar energy potential for urban residential areas in their initial planning and design stages are proposed.
\end{abstract}

\section{Introduction}

Cities are home to more than half of population in the word, consuming most of the energy and resources. The energy problem in urban areas has been an extremely important research field in the process of urban development. As an inexhaustible and clean energy in the world, utilization of solar energy in urban areas has been widely valued by human beings. With the development of solar energy and building integration technology, scholars began to study the design method which takes solar energy utilization as a target variables. For example, Mitja Košira et al [1] studied seven typical cases of Slovenian cities in Europe from the perspective of solar radiation and sunshine time of building envelope, and analyzed the relationship between building density, layout organization and orientation with solar radiation and sunshine time of building envelope. Kanters jouri et al [2] used the design layout, building density and orientation as the guidance and control indicators to parameterize the solar energy potential of four common urban block design schemes in Sweden. Sarralde, Juan José et al [3]discussed the relationship between urban morphology and urban solar energy collection. It analyzes the different possibilities of urban form in London and tests the variables of urban form in order to increase the solar energy potential of the region. Christina Chatzipoulka et al [4]discussed the relationship between design variables and the solar energy utilization potential of the building facade and the ground. Itis based on morphological and solar energy analysis of 24 urban forms in London,

*Corresponding author: liuyu@nwpu.edu.cn 
covering various building density values found in the whole city. Li Dapeng et al [5] studied the relationship between the solar energy utilization potential and the aspect ratio, azimuth angle and coverage rate of low, medium and high density residential buildings in Beijing from the perspective of solar energy potential, including active and passive thermal utilization potential. From the perspective of solar radiation distribution, Liao Wei et al [6] discussed the new scientific problem of large-scale application of solar energy buildings: the impact of urban form on available solar energy resources. Through computer simulation research, the influence of different prototype forms on solar radiation distribution was obtained. From the perspective of facade solar energy potential.

These studies range from building and community to urban and regional scale. They mainly focus on active or passive thermal utilization solar radiation, and their relationship with guidance and control indicators for building design. However, few research has taken the following three aspects as their result orientation: annual average solar radiation per unit area, building surface area with solar energy potential, and amount of solar radiation with potential of utilization. This paper studies the annual average solar radiation per unit area of residential buildings, the surface/facade area of residential buildings with solar energy potential, and the amount of potentially usable solar radiation with some building density related variables (including building density, plot ratio, building layout and building height). The objectives of the study are:

(1) Quantify the effectiveness of the solar energy utilization.

(2) Comparing the effectiveness of solar energy utilization at different building densities.

\section{Research contents and methods}

\subsection{Solar radiation in Xining City}

Xining is the capital city of Qinghai Province located in northwest of China. With an annual total solar radiation ranges from $5180-6337 \mathrm{MJ} / \mathrm{m}^{2}$ and an large number of days with more than 6 hours/day of sunshine in Xining is 251.2-265.5, Xining city has great potential for solar energy utilization [7].

\subsection{Analysis of residential morphology in Xining City}

Fig. 1 left shows that the three main types of building layout are determinant, enclosed and point in which the determinant type accounts for the largest proportion (73\%).Further analyzes reveals that within the determinant type, normal parallel from accounts for nearly half $(51 \%)$ of them, followed by gable misalignment style (15\%) and south low-north high style $(10 \%)$ (Fig. 1 right). Therefore, further study of this paper focused on these three high ranking layouts: parallel determinant (51\%), transverse misalignment (15\%) and gable misalignment $(6 \%)$. 

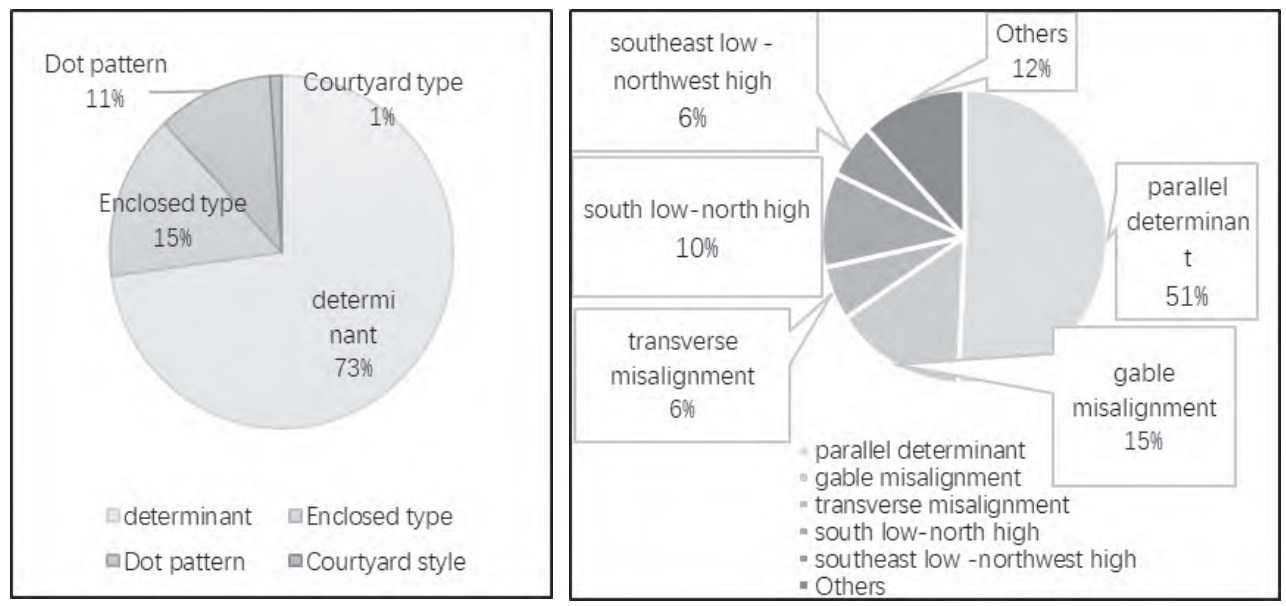

Fig. 1. Statistical chart of building layout types and forms.

\subsection{Establishment of generic model}

According to the statistical analysis results, 36 generic models of Xining residential area are established. The simplified general model of various densities is on a hypothetical site of $400 \times 250 \mathrm{~m}$. Density is determined by four different indicators: layout type, building density, floor number and floor area ratio.

The generic models were formed into six layout forms (see Tab. 1). The key variables involved are defined in Tab. 2. Such models (see Tab. 3) were established to explore the solar utilization potential of different building densities with different types/forms of building layout. Each of them represents a specific combination of building layout and density in low-rise, middle-rise and high-rise residential areas. These generic models are established based on typical values of the floor area ratio and the most widely distributed building layout types/forms in Xining city.

\subsection{Software simulation}

Rhinoceros 6.0 and its plug-in grasshopper were used for simulation. The specific solar radiation value is displayed in a linear proportion within a specified range, which changes gradually from white-blue-yellow-red through the spectrum. The closer the color to red, the greater the solar radiation is. According to the research of Compagnon[16], the threshold value for photovoltaic application is set as $800 \mathrm{KWh} / \mathrm{m}^{2}$, for heat collection is set as 400 $\mathrm{KWh} / \mathrm{m}^{2}$, and for passive thermal utilization is set as $216 \mathrm{KWh} / \mathrm{m}^{2}$. When the received solar radiation is less than the above threshold value, the color is represented by white.

Table 1. Six layout forms of the the generic models.

\begin{tabular}{|c|c|c|c|c|c|}
\hline $\begin{array}{l}E=-z= \\
z=-z=\end{array}$ & 를ㄹㄹㄹㄹㄹㄹㄹㄹㄹㄹㄹㄹㄹㄹㄹㄹㄹ일 & $\begin{array}{l}\square-a-2 \\
-\pi-\pi=\end{array}$ & 드ㄹㅡㅡ르르르를 & 프⼆ㅡㅡㅡㅡ & 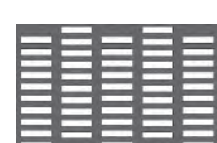 \\
\hline A1 & A1 & B1 & B2 & $\mathrm{C} 1$ & $\mathrm{C} 2$ \\
\hline $\begin{array}{r}\text { parallel d } \\
\text { A1:18\% }\end{array}$ & $\begin{array}{l}\text { terminant } \\
\text { B1:36\% }\end{array}$ & $\begin{array}{c}\text { transverse } m \\
\text { B1:18\% }\end{array}$ & $\begin{array}{l}\text { isalignment } \\
\text { B2:36\% }\end{array}$ & $\begin{array}{r}\text { gable mis } \\
\text { C1:18\% }\end{array}$ & alignment \\
\hline
\end{tabular}


Table 2. Definition of key variables.

\begin{tabular}{|c|c|}
\hline $\begin{array}{c}\text { Annual average solar radiation per } \\
\text { unit area (external surface/facade) }\end{array}$ & $\begin{array}{c}\text { The amount of solar radiation per unit area received on a } \\
\text { given external surface or facade within a year }\end{array}$ \\
\hline $\begin{array}{c}\text { Annual average solar radiation per } \\
\text { unit building area }\end{array}$ & $\begin{array}{c}\text { The ratio of the total amount of solar radiation received by } \\
\text { the external surface of a building to the building area in a } \\
\text { year }\end{array}$ \\
\hline $\begin{array}{c}\text { Photovoltaic potential } \\
\text { area(external surface/facade) }\end{array}$ & $\begin{array}{c}\text { The area where the received solar radiation is greater than or } \\
\text { equal to the preset threshold value of photovoltaic utilization } \\
\text { (external surface/facade) }\end{array}$ \\
\hline $\begin{array}{c}\text { Potential area of heat collection } \\
\text { utilization (external } \\
\text { surface/facade) }\end{array}$ & $\begin{array}{c}\text { The area where the received solar radiation is greater than or } \\
\text { equal to the preset threshold value of heat collection } \\
\text { utilization (external surface/facade) }\end{array}$ \\
\hline $\begin{array}{c}\text { Potential area of passive thermal } \\
\text { utilization (external } \\
\text { surface/facade) }\end{array}$ & $\begin{array}{c}\text { The area where the received solar radiation is greater than or } \\
\text { equal to the preset threshold of passive thermal utilization } \\
\text { (external surface/facade) }\end{array}$ \\
\hline $\begin{array}{c}\text { Photovoltaic potential solar } \\
\text { radiation (external surface/facade) }\end{array}$ & $\begin{array}{c}\text { The sum of solar radiation energy received in one year is } \\
\text { greater than or equal to the preset threshold value of } \\
\text { photovoltaic utilization (external surface/facade) }\end{array}$ \\
\hline $\begin{array}{c}\text { Solar radiation with heat } \\
\text { collection potential (external } \\
\text { surface/facade) }\end{array}$ & $\begin{array}{c}\text { The sum of solar radiation energy received in one year is } \\
\text { greater than or equal to the preset threshold value of heat } \\
\text { collection utilization (external surface/facade) }\end{array}$ \\
\hline $\begin{array}{c}\text { Passive thermal potential solar } \\
\text { radiation (external surface/facade) }\end{array}$ & $\begin{array}{c}\text { The sum of solar radiation energy received in one year is } \\
\text { greater than or equal to the preset threshold of passive } \\
\text { thermal utilization (external surface/facade) }\end{array}$ \\
\hline
\end{tabular}


Table 3. Parameters of the generic models.

\begin{tabular}{|c|c|c|c|c|c|}
\hline \multicolumn{3}{|c|}{ Layout Forms } & \multirow{2}{*}{ Building Density } & \multirow{2}{*}{$\begin{array}{l}\text { Number of } \\
\text { Floors }\end{array}$} & \multirow{2}{*}{ Plot Ratio } \\
\hline Code & Number & Description & & & \\
\hline \multirow{8}{*}{ A1 } & 1 & \multirow{8}{*}{$\begin{array}{c}\text { parallel } \\
\text { determinant }\end{array}$} & $18 \%$ & 3 & 0.54 \\
\hline & 2 & & $18 \%$ & 6 & 1.08 \\
\hline & 3 & & $18 \%$ & 9 & 1.62 \\
\hline & 4 & & $18 \%$ & 12 & 2.16 \\
\hline & 5 & & $18 \%$ & 15 & 2.7 \\
\hline & 6 & & $18 \%$ & 18 & 3.24 \\
\hline & 7 & & $18 \%$ & 21 & 3.78 \\
\hline & 8 & & $18 \%$ & 24 & 4.32 \\
\hline \multirow{4}{*}{ A2 } & 1 & \multirow{4}{*}{$\begin{array}{c}\text { parallel } \\
\text { determinant }\end{array}$} & $36 \%$ & 3 & 1.08 \\
\hline & 2 & & $36 \%$ & 6 & 2.16 \\
\hline & 3 & & $36 \%$ & 9 & 3.24 \\
\hline & 4 & & $36 \%$ & 12 & 4.32 \\
\hline \multirow{8}{*}{ B1 } & 1 & \multirow{8}{*}{$\begin{array}{c}\text { transverse } \\
\text { misalignment }\end{array}$} & $18 \%$ & 3 & 0.54 \\
\hline & 2 & & $18 \%$ & 6 & 1.08 \\
\hline & 3 & & $18 \%$ & 9 & 1.62 \\
\hline & 4 & & $18 \%$ & 12 & 2.16 \\
\hline & 5 & & $18 \%$ & 15 & 2.7 \\
\hline & 6 & & $18 \%$ & 18 & 3.24 \\
\hline & 7 & & $18 \%$ & 21 & 3.78 \\
\hline & 8 & & $18 \%$ & 24 & 4.32 \\
\hline \multirow{4}{*}{ B2 } & 1 & \multirow{4}{*}{$\begin{array}{c}\text { transverse } \\
\text { misalignment }\end{array}$} & $36 \%$ & 3 & 1.08 \\
\hline & 2 & & $36 \%$ & 6 & 2.16 \\
\hline & 3 & & $36 \%$ & 9 & 3.24 \\
\hline & 4 & & $36 \%$ & 12 & 4.32 \\
\hline \multirow{8}{*}{$\mathrm{C} 1$} & 1 & \multirow{8}{*}{$\begin{array}{c}\text { gable } \\
\text { misalignment }\end{array}$} & $18 \%$ & 3 & 0.54 \\
\hline & 2 & & $18 \%$ & 6 & 1.08 \\
\hline & 3 & & $18 \%$ & 9 & 1.62 \\
\hline & 4 & & $18 \%$ & 12 & 2.16 \\
\hline & 5 & & $18 \%$ & 15 & 2.7 \\
\hline & 6 & & $18 \%$ & 18 & 3.24 \\
\hline & 7 & & $18 \%$ & 21 & 3.78 \\
\hline & 8 & & $18 \%$ & 24 & 4.32 \\
\hline \multirow{4}{*}{$\mathrm{C} 2$} & 1 & \multirow{4}{*}{$\begin{array}{l}\text { gable } \\
\text { misalignment }\end{array}$} & $36 \%$ & 3 & 1.08 \\
\hline & 2 & & $36 \%$ & 6 & 2.16 \\
\hline & 3 & & $36 \%$ & 9 & 3.24 \\
\hline & 4 & & $36 \%$ & 12 & 4.32 \\
\hline
\end{tabular}




\section{Results of the simulations}

\subsection{Annual average solar radiation per unit area}

\subsubsection{Annual average solar radiation per unit external surface area}

Forms with higher building densities possesses larger amount of annual average solar radiation per unit external surface area than those with lower building densities. This may because that high density results in an increased roof area. With an increase of plot ratio, the amount of annual average solar radiation per unit external surface area decreases. However, when the floor area ratio is equal to or greater than 3.24 , results of the six different forms, which possess different building densities, reach similar values. This shows that, when the plot ratio is low, the layout with high density can obtain more annual average solar radiation per unit surface than the layout with low density (Fig.2).

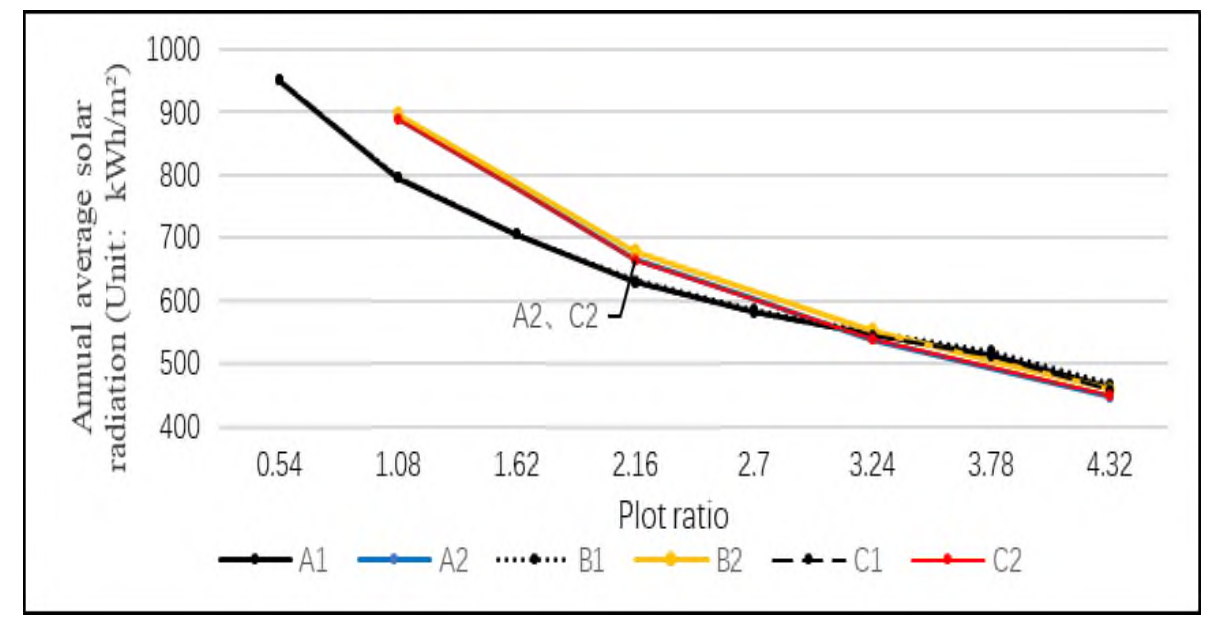

Fig. 2. Annual average solar radiation per unit external surface area.

\subsubsection{Annual average solar radiation per unit facade area}

The amount of annual average solar radiation per unit facade area of form A1, B1, C1 which possess a density of $18 \%$ is significantly larger than that of $\mathrm{A} 2, \mathrm{~B} 2$ and $\mathrm{C} 2$ with a density of $36 \%$. There is little difference among forms A1, B1 and $\mathrm{C} 1$, while density results of form B2 is significantly higher than that of $\mathrm{A} 2$ and $\mathrm{C} 2$. The annual average solar radiation of form $\mathrm{B} 1$ is higher than that of the other five forms, while that of from $\mathrm{A} 2$ and $\mathrm{C} 2$ are the lowest (Fig.3). 


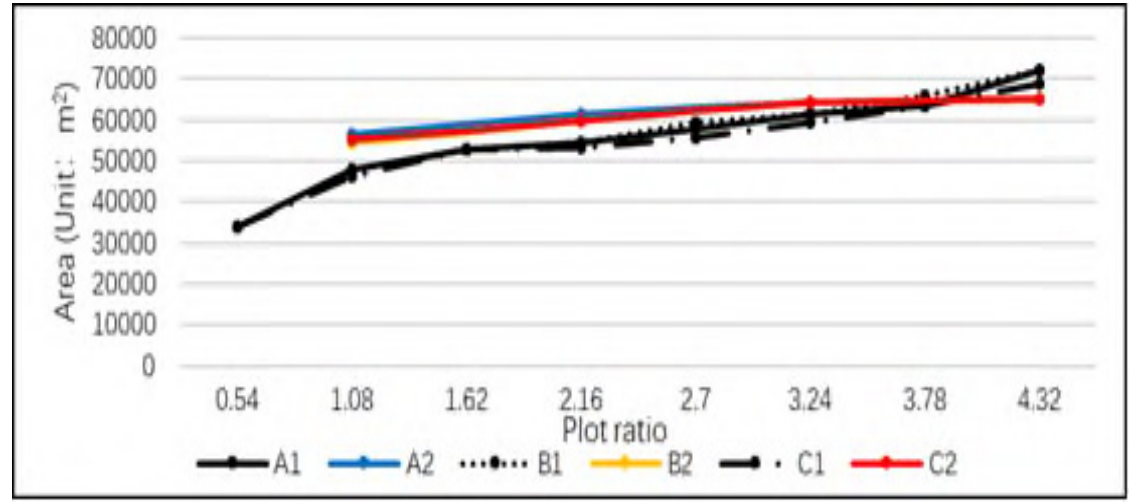

Fig. 3. Annual average solar radiation per unit facade area.

\subsubsection{Annual average solar radiation per unit construction area}

With the increase of plot ratio, the amount of annual average solar radiation per unit construction area of the forms with higher building densities is greater than that of the form with lower building densities, and form B2 is the highest. However, when the floor area ratio is greater than or equal to 3.78 , the amount of annual average solar radiation per unit construction area of forms with lower building density is gradually higher than that of the forms with higher building density. Therefore, we can draw a preliminary conclusion that in the case of low, medium plot ratio, the layout with higher building density can increase the solar radiation per unit building area under the three layouts of parallel determinant, transverse staggered type and gable staggered type (Fig.4).

The amount of annual average solar radiation per unit facade area of form A1, B1, C1 which possess a density of $18 \%$ is significantly larger than that of $\mathrm{A} 2, \mathrm{~B} 2$ and $\mathrm{C} 2$ with a density of $36 \%$. There is little difference among forms $\mathrm{A} 1, \mathrm{~B} 1$ and $\mathrm{C} 1$, while density results of form B2 is significantly higher than that of A2 and $\mathrm{C} 2$. The annual average solar radiation of form $\mathrm{B} 1$ is higher than that of the other five forms, while that of from $\mathrm{A} 2$ and C2 are the lowest. (Fig.3)

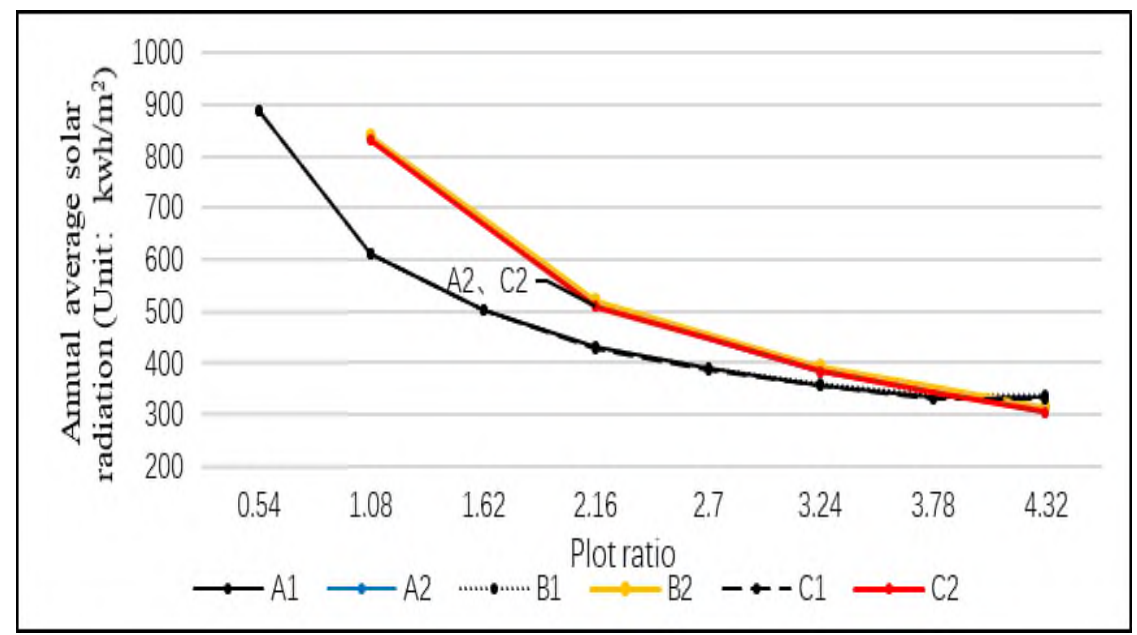

Fig. 4. Annual average solar radiation per unit building area. 


\subsection{Annual average solar radiation per unit area}

\subsubsection{Area of external surface with solar energy potential}

When the plot ratio is at medium high value, with the increase of plot ratio, the form with small building density rate will gradually exceed the form with larger building density rate. In different solar energy utilization modes, the intersection points are different. In the utilization of solar photovoltaic, the reverse overrun occurs only when the floor area ratio reaches about 3.78, and in the heat collection utilization and passive type. In terms of heat utilization, only a floor area ratio of 2.16-2.7 is needed. This shows that the area of solar energy collection and passive heat utilization can be increased by appropriately increasing the building density rate in low and medium floor area ratio (Fig.5-7).

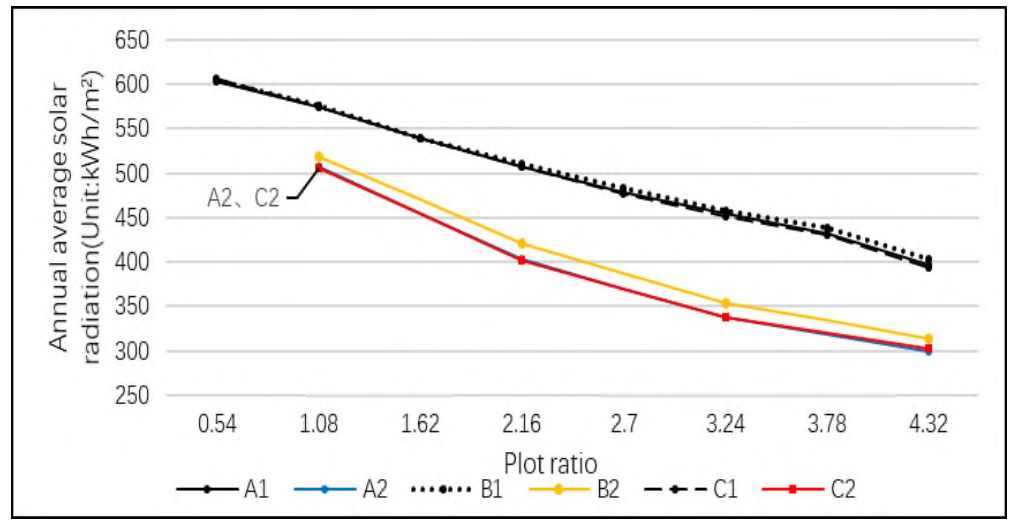

Fig. 5. Potential area analysis of photovoltaic utilization on external surface.

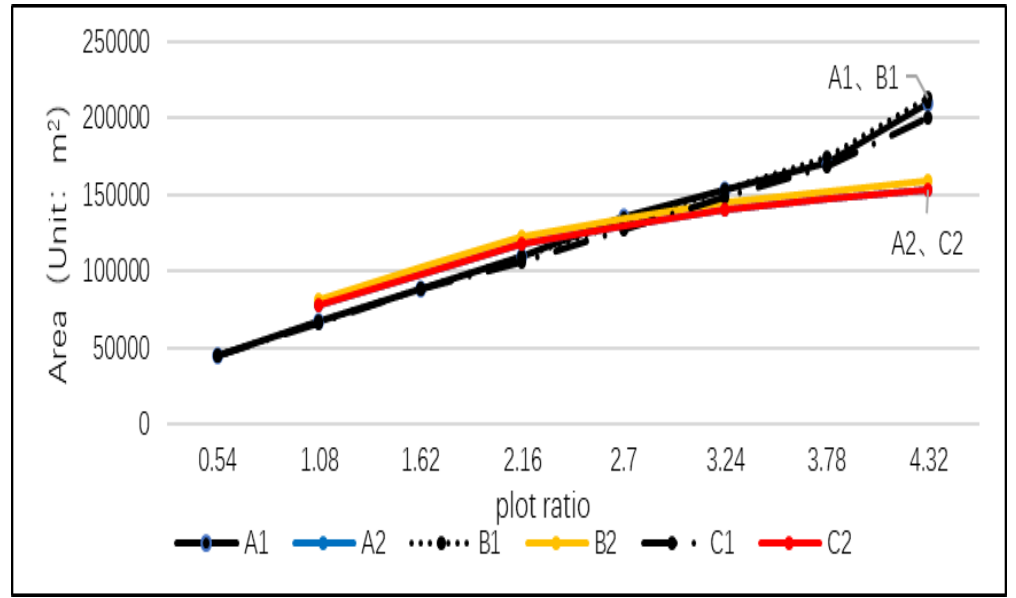

Fig. 6. Potential area analysis of heat collection utilization on external surface. 


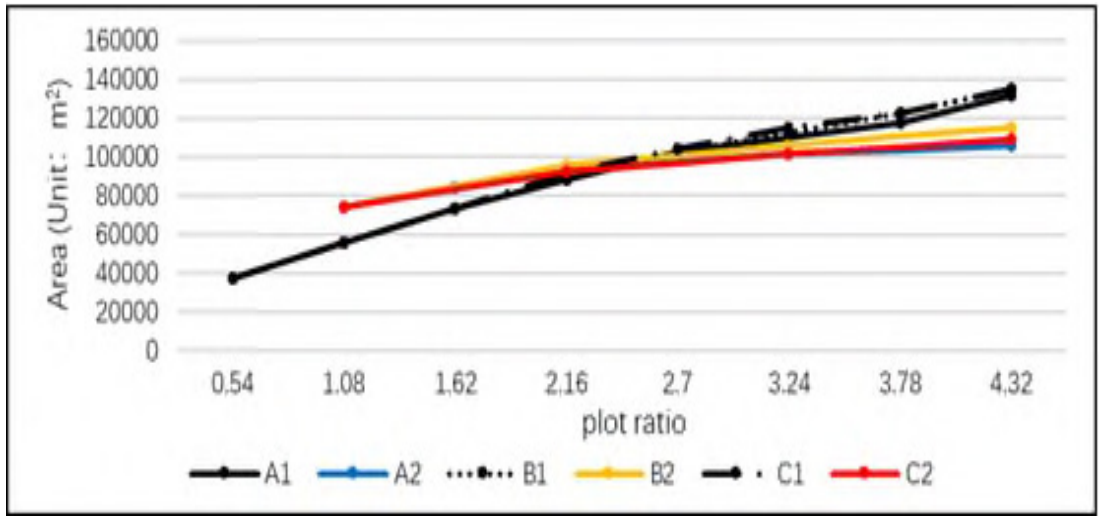

Fig. 7. Potential area analysis of passive heat utilization on external surface.

\subsubsection{Area of facade with solar energy potential}

No matter how the plot ratio changes, the form with lower building density has significant advantages in solar photovoltaic utilization and passive heat utilization. On the other hand, when the plot ratio is low, the form with larger building density is more dominant. form $\mathrm{B}$ is better than form $\mathrm{A}$ and form $\mathrm{C}$ in solar energy collection and passive heat utilization. (Fig.8-10).

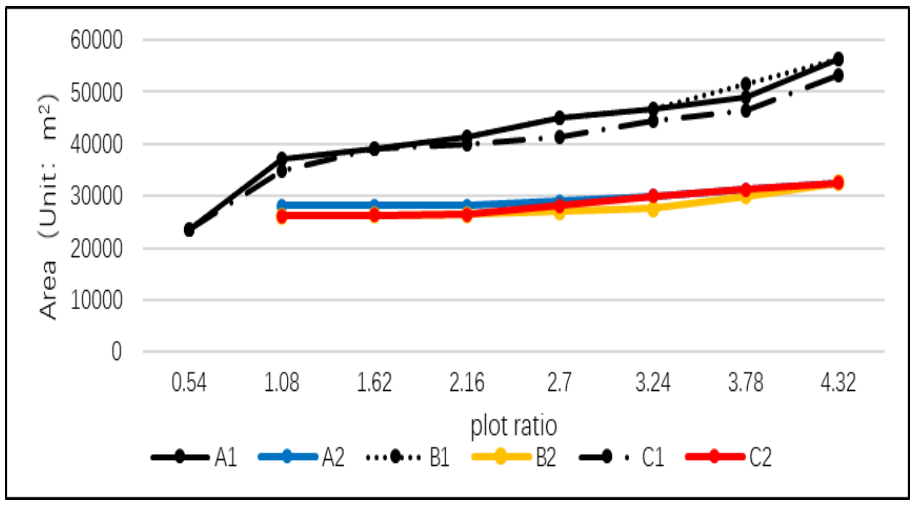

Fig. 8. Potential area analysis of photovoltaic utilization on façade.

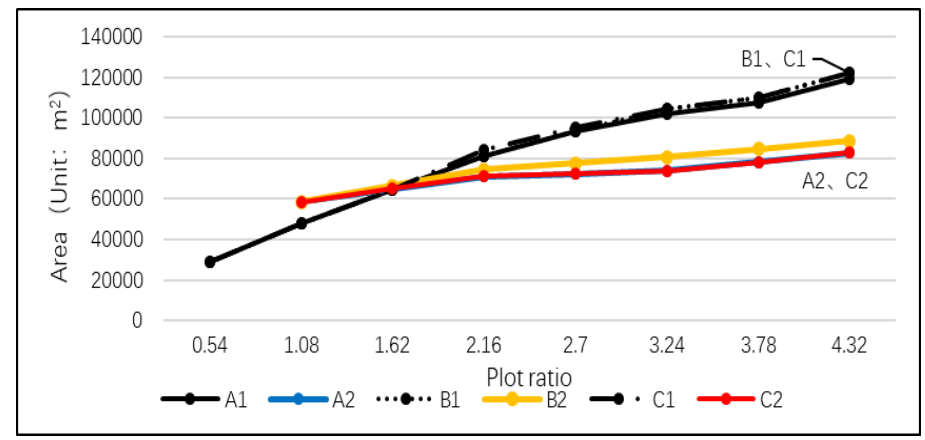

Fig.9. Potential area analysis of heat collection utilization on façade. 


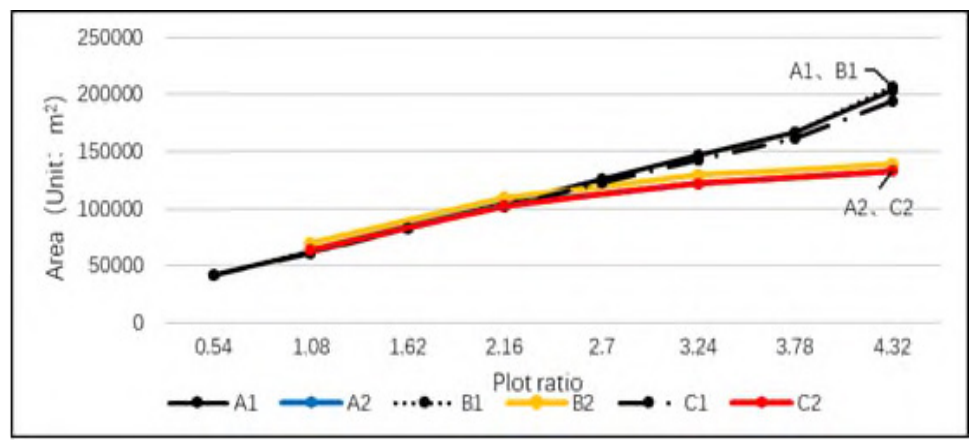

Fig. 10. Potential area analysis of passive heat utilization on façade.

\subsection{Solar radiation with solar energy potential}

\subsubsection{Analysis of solar radiation on external surface}

The solar radiation obtained by the external surface is always much higher than that of the form with small building density no matter how the plot ratio changes, unless the floor area ratio is particularly high. And among the three building layout forms, transverse misalignment has better application advantages in heat collection and passive heat utilization, the advantage is more obvious when the building density is larger. (Fig.11-12)

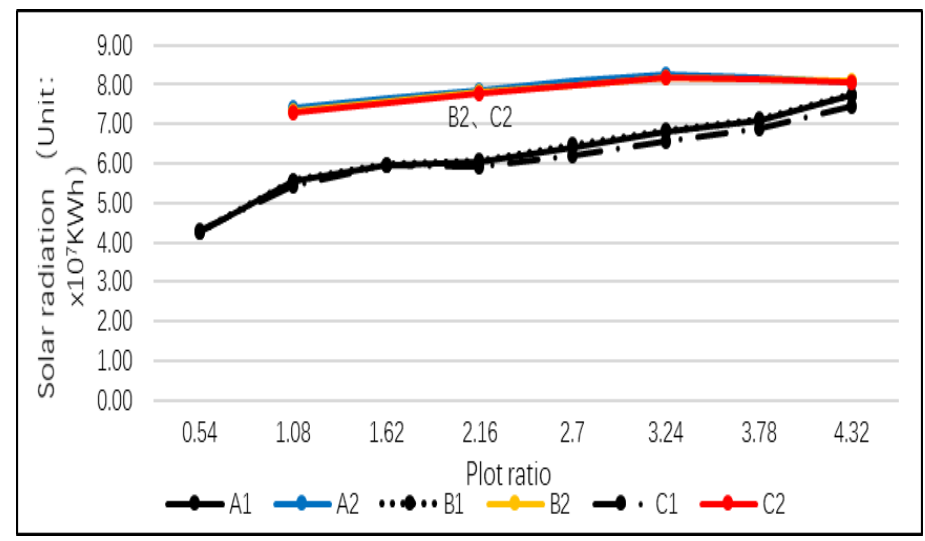

Fig. 11. Solar radiation in Photovoltaic utilization of external surface.

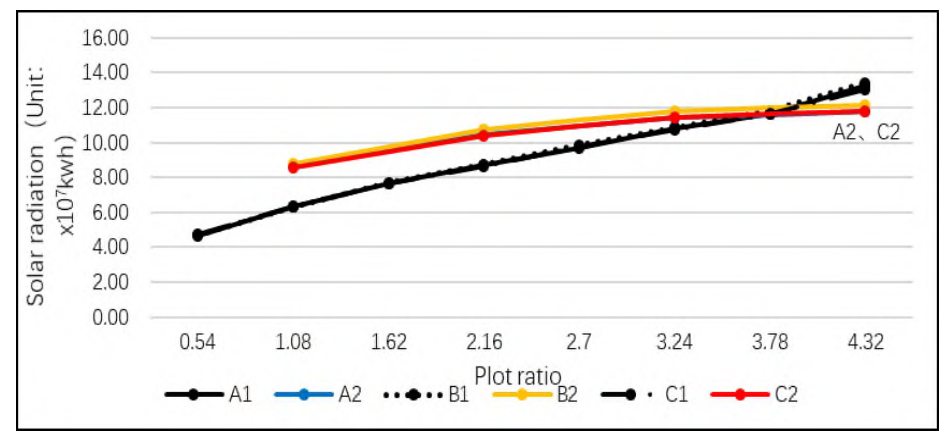

Fig. 12. Solar radiation in heat collection utilization of external surface. 


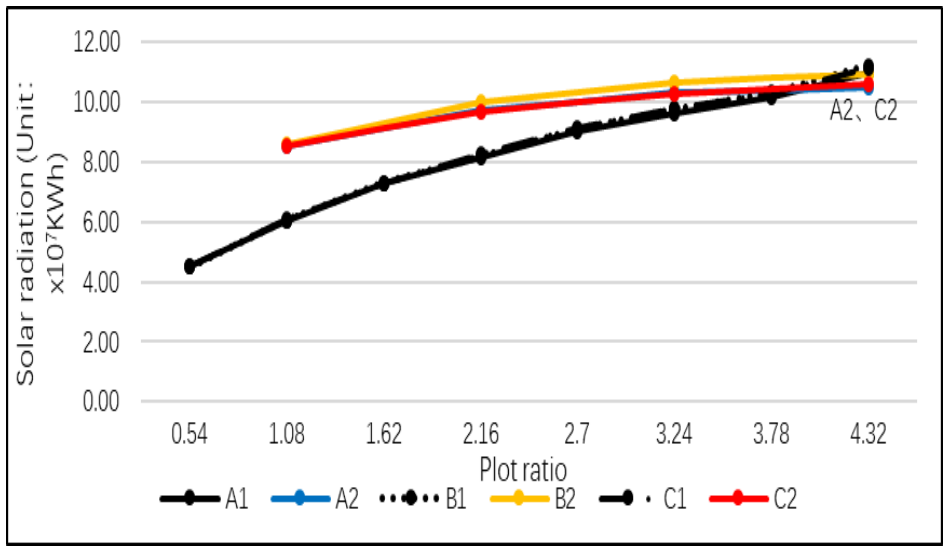

Fig. 13. Solar radiation in passive heat utilization of external surface.

\subsubsection{Solar radiation on building facade}

The building density has a greater impact on the solar radiation of the facade. The lower the building density is, the greater the solar radiation on the facade is. Among the three layout forms, the transverse misalignment has better advantages in solar radiation acquisition, whether in photovoltaic utilization, heat collection utilization or passive thermal utilization. And the higher the density, the more obvious the utilization advantage (Fig.14-16).

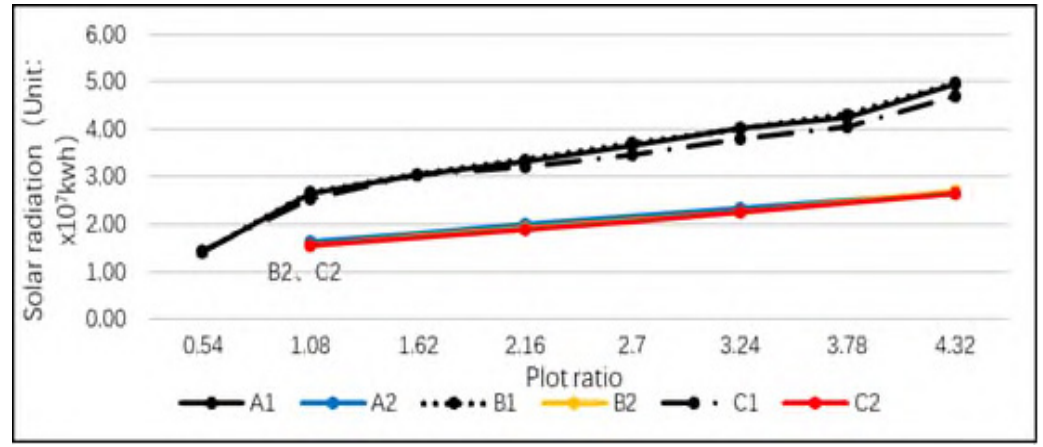

Fig. 14. Solar radiation in Photovoltaic utilization of façade.

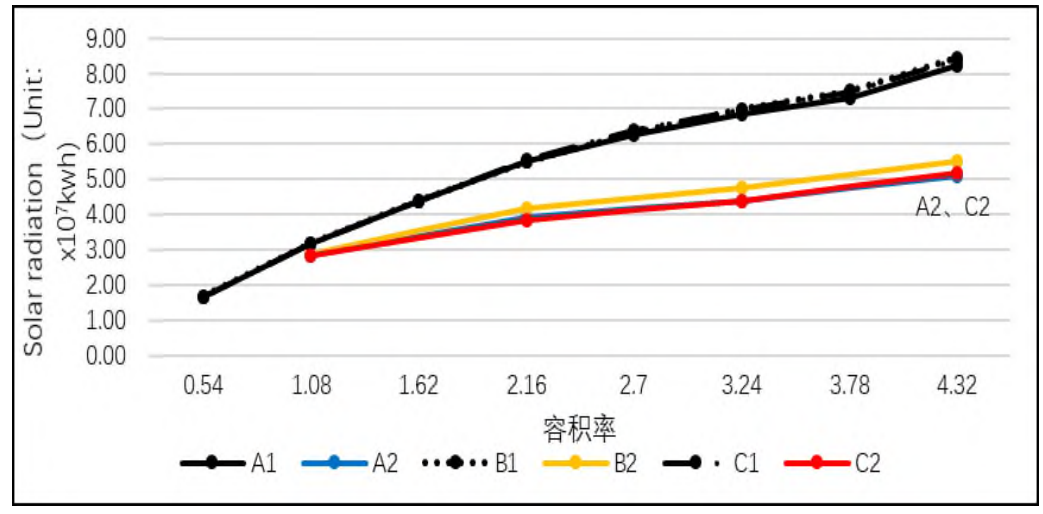

Fig. 15. Solar radiation in heat collection utilization of façade. 


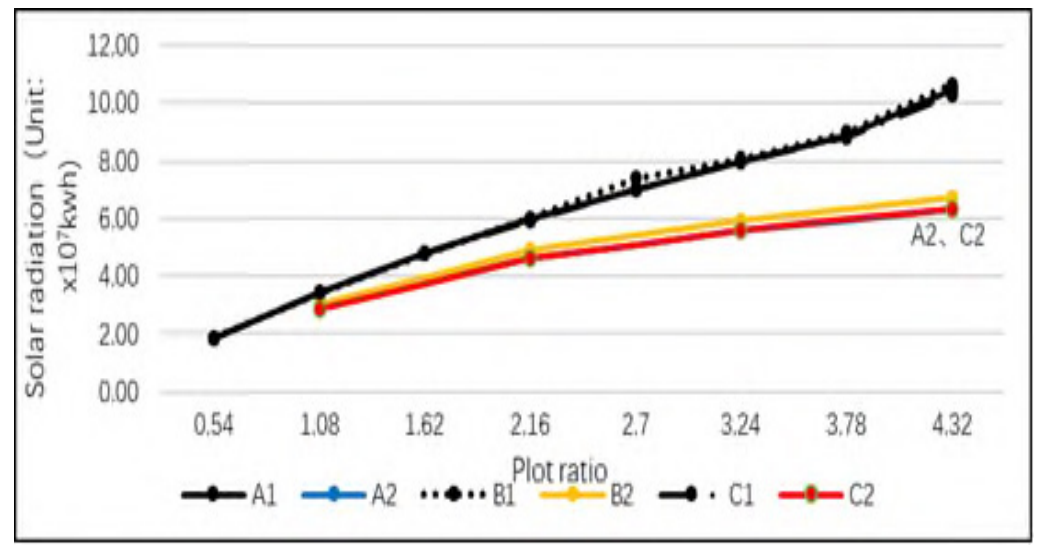

Fig. 16. Solar radiation in passive heat utilization of façade.

\section{References}

1. M. Kosir, G. I. Capeluto, A. Krainer, Z. Kristl, Energy Policy, 69, 443-456 (2014)

2. J. Kanters, M. Wall, Urban Planning, 48, 1607-1616 (2014)

3. J.J. Sarralde, D.J. Quinn, D. Wiesmann, K. Steemers, Renewable Energy, 73, 10-17 (2015)

4. C. Chatzipoulka, R. Compagnon, M. Nikolopoulou, Solar Energy, 138, 53-66 (2016)

5. D.Li, G. Liu, S. Liao, Solar Energy, 111, 225-235 (2015)

6. W. Liao, M. Xu, B.J. Lin, Huazhong architecture, 31(04), 64-66 (2013)

7. R. Compagnon, Energy and Buildings, 36(4), 321-328 (2004) 